\title{
ACIDENTE OFÍDICO EM EQUINO NO MUNICIPIO DE ITUVERAVA-SP RELATO DE CASO
}

\author{
CANO, Letícia Silva ${ }^{1}$ \\ LIMA, Bruna Bressianini \\ ZERO, Raphael Chiarelo \\ CARNEIRO, Lucas Gléria \\ PALAZZO, Elzylene Léga ${ }^{1}$ \\ MONTELLO, Joel de Souza
}

RESUMO: O trabalho teve como objetivo relatar um caso de acidente ofídico em um equino, macho, da raça Mangalarga Marchador de seis anos de idade, encaminhado para o Hospital Veterinário da Faculdade Dr. Francisco Maeda FAFRAM Ituverava-SP, apresentando dificuldade respiratória, edema de focinho, epistaxe bilateral e desidratação. Após exames físico e laboratorial foi confirmado o diagnóstico de acidente ofídico do gênero Botrophs e instituído o tratamento com fluidoterapia, antibioticoterapia, antiinflamatórios esteroidais e não esteroidais, hepatoprotetores e transfusão sanguínea. O animal se recuperou totalmente e obteve alta médica após seis dias.

Palavras-chave: Toxina. Bothrops sp. Transfusão.

\section{OPHIDIAN ACCIDENT IN HORSE AT ITUVERAVA-SP - CASE REPORT}

SUMMARY: This study aims to report a case of snakebite in an equine, male, Mangalarga Marchador six years old , referred to the Veterinary Hospital of the Faculty Dr. Francisco Maeda FAFRAM Ituverava -SP, having difficulty breathing, nose edema, epistaxis bilateral and dehydration. After examination, physical and laboratory confirmed the diagnosis of snakebite of gender Botrophs and treatment instituted with fluid therapy , antibiotics , NSAIDs nonsteroidal, hepatoprotective and blood transfusion. The animal has fully recovered and was discharged from medical after six days.

Keywords: Toxin. Bothrops sp. Transfusion.

\section{INTRODUÇÃO}

Os gêneros Bothrops, Crotalus e Lachesis pertencentes à Família Viperida e correspondem às serpentes causadoras de acidentes ofídicos mais relevantes no Brasil, sendo que as primeiras são responsáveis por cerca de 80 a 90\% dos acidentes ofídicos em seres humanos. Tal gênero corresponde também à grande maioria dos casos de acidentes ofídicos em animais (CALDAS, et al., 2008; CHIACCHIO et al., 2010). 
As espécies como Jararaca, Jaracussu e Urutu pertencentes ao gênero Bothrops têm preferência por lugares úmidos, plantações e pastagens; sua alimentação inclui roedores e possuem hábitos noturnos. Seu comportamento agressivo faz com que, quando ameaçadas desferem botes sem produzir ruídos (BRASIL, 2001).

O local da picada possui variação conforme o comportamento do animal; devido sua curiosidade e posição para se alimentar, sendo que a região mais afetada é a cabeça, em especial focinho, região submandibular e língua; embora os membros torácicos, pélvicos e úberes sejam comumente atingidos (BICUDO, 2002).

O veneno das serpentes do gênero Bothrops atua de diferentes formas quando disseminado no organismo animal eseu efeito possui ação proteolítica, coagulante e hemorrágica (ARCOLINI, 2006).

Segundo Tokarnia e Peixoto (2006), o veneno botrópico possui complexa mistura de enzimas, peptídeos e proteínas como metaloproteases, citolisinas, hialuronidase, fosfolipases e esterases, que provocam quadro de inflamação local, necrose e dano ao epitélio vascular. As ações mais relevantes do envenenamento botrópico são classificadas em proteolítica ou necrosante, vasculotóxica e nefrotóxica. As demais ações incluem choque, coagulação intravascular disseminada (CID) e insuficiência renal secundária.

Em relação à suscetibilidade da espécie animal aos efeitos do veneno ofídico, existe uma considerável diferença; estudos comprovaram que equinos, bovinos e ovinos são mais sensíveis seguidos de maneira decrescente por caprinos, caninos, coelhos, suínos, e felinos (TOKARNIA; PEIXOTO, 2006). Porém, devido ao tamanho corporal dos grandes animais, se torna necessário uma maior dose de veneno para provocar óbito. A espécie eqüina ainda parece ser a mais suscetível ao veneno do que qualquer outra (BICUDO, 2002). Neste sentido, o objetivo deste presente trabalho foi relatar um caso de acidente ofídico do gênero Bothrops ocorrido no município de Ituverava-SP, atendido no Hospital Veterinário da Faculdade Dr. Francisco Maeda (FAFRAM), bem como descrever os sinais clínicos decorrentes desta grave afecção e as considerações importantes para o sucesso do tratamento.

\section{RELATO DE CASO}

Um cavalo da raça Mangalarga Marchador, macho, castrado, com aproximadamente seis anos de idade, $400 \mathrm{~kg}$, mantido em piquete de tifton deu entrada no Hospital Veterinário da Faculdade Dr. Francisco Maeda, Ituverava-SP com histórico de inapetência, decúbito prolongado e epistaxe, decorrentes de um possível acidente ofídico. Ao exame físico geral, observou-se frequência cardíaca de 80 batimentos por minuto; frequência respiratória de 50 movimentos respiratórios por minuto; motilidade intestinal normal em todos os quadrantes; temperatura 
corpórea de 38,1 $\mathrm{C}^{\circ}$; tempo de perfusão capilar de três segundos; desidratação de aproximadamente $7 \%$ e mucosas hipercoradas. Aumento considerável de volume na região do focinho e lábios também foi observado, além de epistaxe bilateral (figura 1) e presença de miíase na cavidade oral, na face interna do lábio inferior (figura 2). Episódios de crises convulsivas também foram observados.

O animal foi submetido a exames laboratoriais, tais como hemograma e perfis bioquímicos durante o período em que permaneceu internado (quadro 1).

Figura-1: Imagem fotográfica de um equino com epistaxe (A) e aumento de volume na região labial (B) e focinho (C) após acidente ofídico. Hospital Veterinário-FAFRAM. Ituverava, SP. 2015.

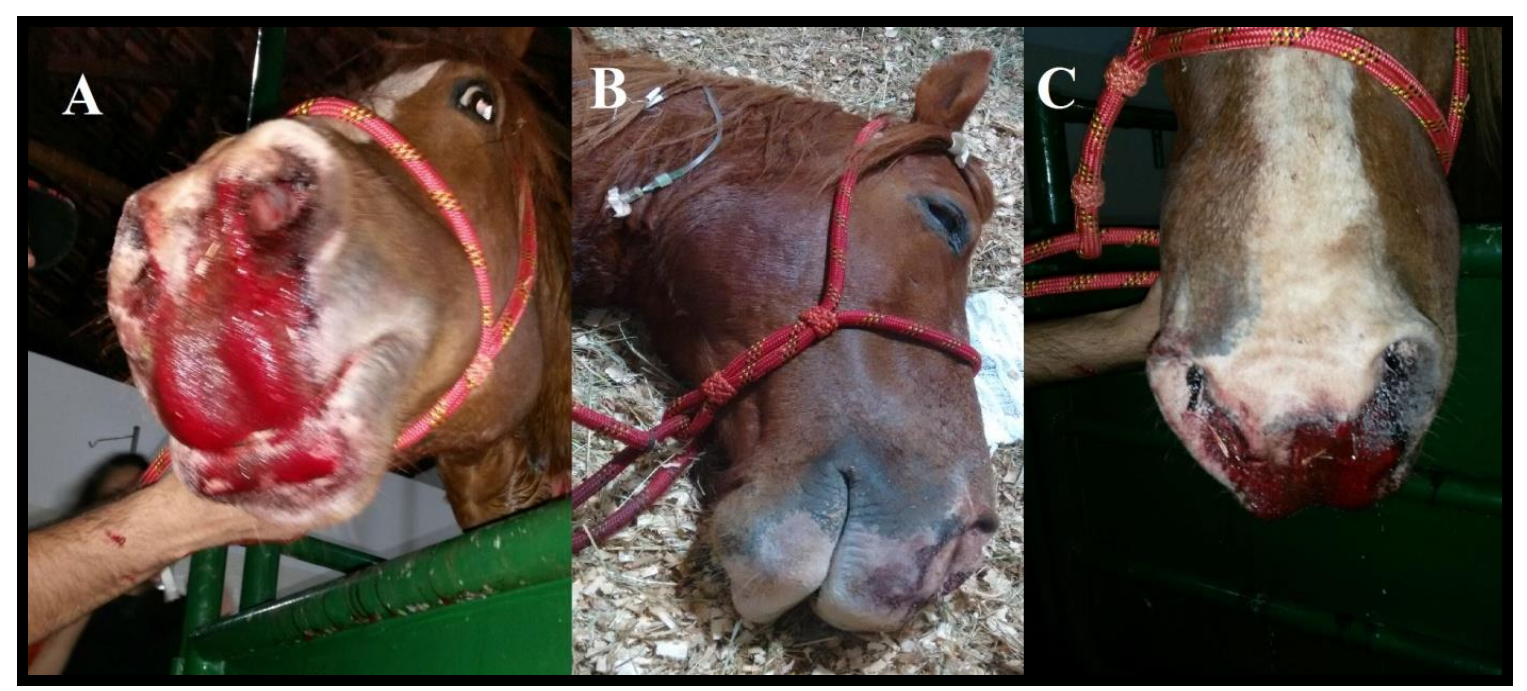

Fonte: Arquivo pessoal (2015).

Figura-2: Imagem fotográfica de miíase (seta) na cavidade oral de um eqüino após acidente ofídico. Hospital Veterinário-FAFRAM. Ituverava, SP. 2015.

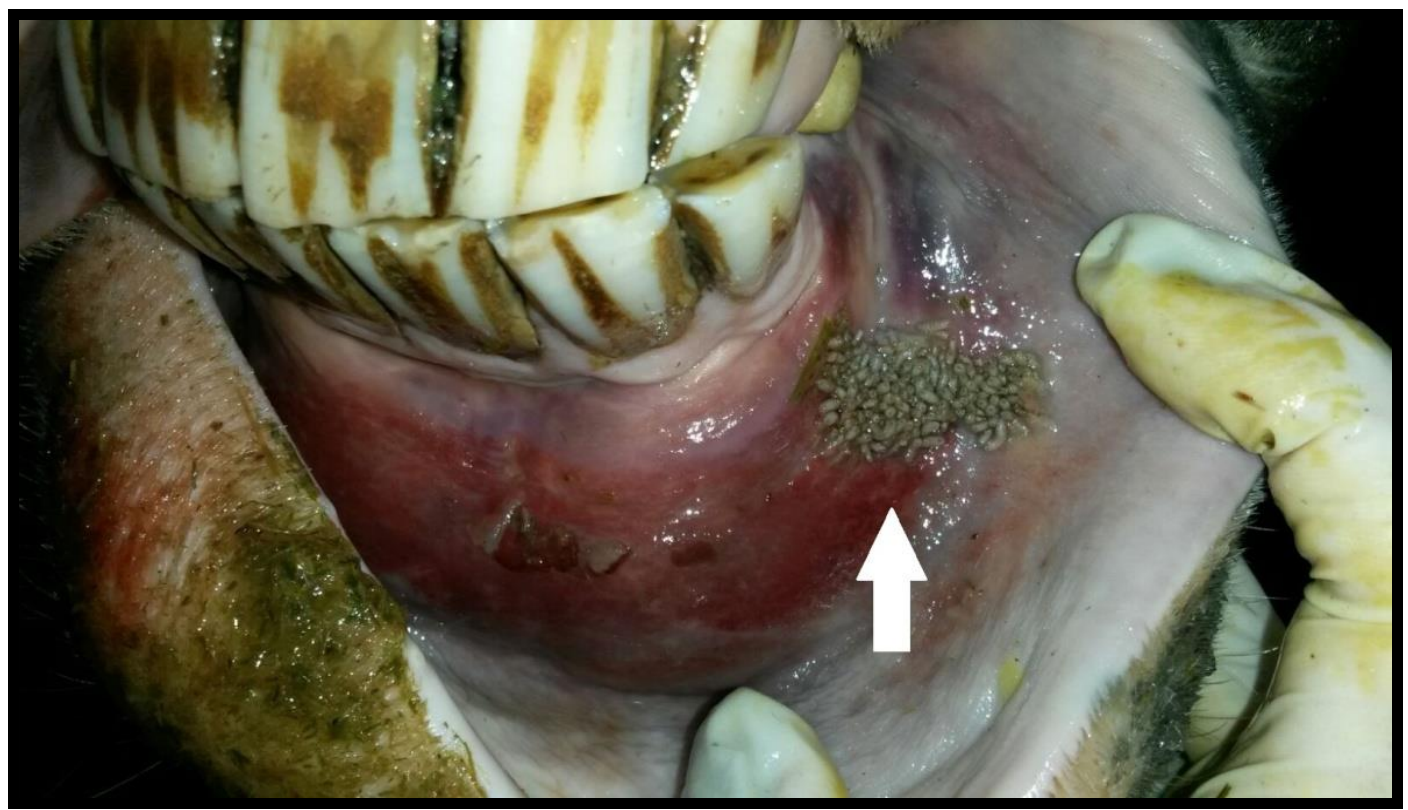

Fonte: Arquivo pessoal (2015). 
Depois de instituído o diagnóstico, o animal foi submetido a tratamento com $160 \mathrm{ml}$ de soro antiofídico polivalente, IV, em dose única; soro antitetânico liofilizado, IM, em dose única; antiinflamatório esteroidal a base de dexametazona $\left(0,1 \mathrm{mg} \cdot \mathrm{kg}^{-1}\right.$, IV, SID), por três dias; antibioticoterapia a base de enrofloxacino $\left(6,0 \mathrm{mg} \cdot \mathrm{kg}^{-1}, \mathrm{IV}, \mathrm{SID}\right)$, durante cinco dias; antihemorrágico a base de ácido tranexâmico (20 mg. $\left.\mathrm{kg}^{-1}, \mathrm{IV}, \quad \mathrm{SID}\right)$, durante três dias; antiinflamatório não esteroidal a base de flunexina meglumina $\left(1,1 \mathrm{mg} \cdot \mathrm{kg}^{-1}, \mathrm{IV}\right.$, SID), durante cinco dias; diurético com furosemida $\left(1,5 \mathrm{mg} \cdot \mathrm{kg}^{-1}, \mathrm{IV}\right)$ dose única, bem como reposição da volemia com solução fisiológica $(\mathrm{NaCl}$ 0,9\%) e glicose 5\%; associado a um frasco de polivitamínico do complexo B (IV,BID), durante cinco dias, $50 \mathrm{ml}$ de protetor hepático (IV,SID), durante três dias. Para o controle das crises convulsivas, foi administrado diazepam $\left(0,25 \mathrm{mg} \cdot \mathrm{kg}^{-}\right.$ ${ }^{1}$,IV), quando necessário e compressa com gelo foi aplicada na região afetada durante 20 minutos, três vezes ao dia. Oito litros de sangue total oriundos de três doadores saudáveis foram transfundidos no paciente e devido ao edema local, presença de coágulos sanguíneos e dificuldade respiratória, realizou-se a sondagem nasal, com uma sonda nasogástrica número 18 (figura 3).

A remoção das larvas da miíase foi realizada com auxílio de pinça anatômica dente de rato e a antissepsia foi realizada com solução de clorexidine a $0,2 \%$ na cavidade oral, três vezes ao dia.

Figura-3: Imagem fotográfica de um equino com sonda nasal após acidente ofídico. Hospital Veterinário-FAFRAM. Ituverava, 2015.

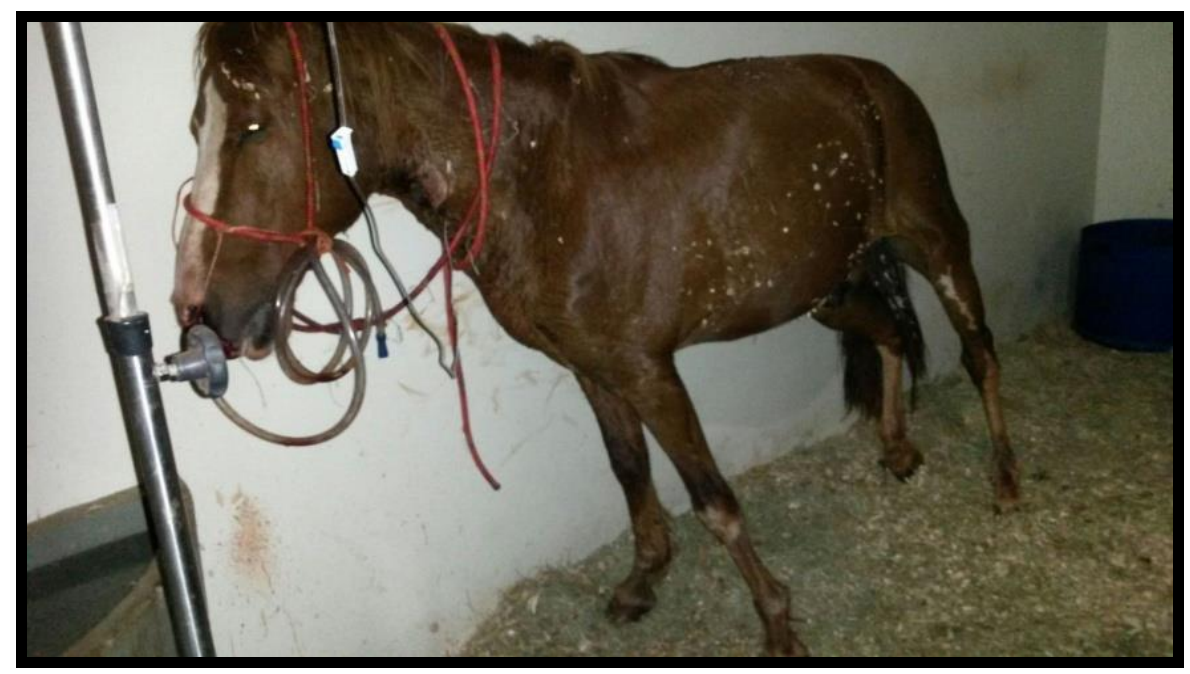

Fonte: Arquivo pessoal (2015). 
Quadro 1: Valores hematológicos e bioquímicos de referência e após acidente ofídico em equinos; Hospital Veterinário, FAFRAM, Ituverava, SP.

\begin{tabular}{|c|c|c|c|c|c|c|}
\hline & & \multicolumn{5}{|c|}{ Dias de internação } \\
\hline & $\begin{array}{l}\text { Valores de } \\
\text { referência }\end{array}$ & 0 & 2 & 3 & 4 & 5 \\
\hline $\begin{array}{l}\text { Eritrócitos } \\
\text { milhões } / \mathrm{mm}^{3}\end{array}$ & $7,0-13$ & 6,3 & 2,4 & 3,9 & 6,2 & 5,1 \\
\hline $\begin{array}{l}\text { Hemoglobina } \\
\text { g/dl }\end{array}$ & $10,0-18$ & 8,6 & 4 & 5,4 & 8,3 & 6,6 \\
\hline $\begin{array}{c}\text { Hematócrito } \\
\%\end{array}$ & $32-55$ & 25 & 10 & 15 & 25 & 20 \\
\hline $\begin{array}{l}\text { Leucócitos } \\
\text { Mil (x103/uL) }\end{array}$ & $7-14$ & 20.100 & 25.200 & 13.280 & 9.000 & 12.000 \\
\hline 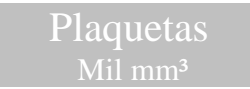 & $200-600$ & 108.575 & 98.400 & 174.200 & 207.050 & 229.000 \\
\hline $\begin{array}{l}\text { Uréia } \\
\mathrm{mg} / \mathrm{dL}\end{array}$ & $21-54$ & 155 & 113 & - & 84 & 52 \\
\hline $\begin{array}{l}\text { Creatinina } \\
\mathrm{Mg} / \mathrm{dL}\end{array}$ & $0,9-1,8$ & 7,0 & 3,8 & - & 1,7 & 1,4 \\
\hline $\begin{array}{c}\text { AST } \\
\text { U/L } \\
\end{array}$ & $226-336$ & - & 623 & - & 754 & 570 \\
\hline $\begin{array}{c}\text { Fosfatase } \\
\text { alcalina } \\
\text { U/L }\end{array}$ & $143-395$ & 107 & 223 & - & 265 & 240 \\
\hline $\begin{array}{l}\text { Fibrinogênio } \\
\text { Mg/dL }\end{array}$ & $200-400$ & 200 & 200 & - & 200 & 200 \\
\hline
\end{tabular}

Fonte: Elaborado pelo autor (2015).

No quinto dia de internação foram repetidos os exames laboratoriais, os quais apresentaram melhora significativa e no sexto dia o animal recebeu alta médica.

\section{RESULTADO E DISCUSSÃO}

A cabeça é o principal local de picadas por ofídicos em animais domésticos, isto ocorre devido a hábitos de curiosidade ou alimentares (GRUNERT; GRUNERT 1969; RADOSTITS et al., 1994), o que coincide com os achados deste relato, tais como edema em focinho e lábios, epistaxe e presença de lesão sugestiva a picada de cobra, o que permitiu estabelecer o diagnóstico de acidente ofídico.

Outras situações também devem ser analisadas como as condições alérgicas com edema localizado, picada de insetos, intoxicações por organofosforados ou por plantas tóxicas, doenças infecciosas como raiva e clostridioses, dentre outras, visando o estabelecimento de um diagnóstico diferencial (GRAÇA et al., 2008). 
Conforme mencionado por Lima et al. (2013), nem sempre é possível identificar a espécie de serpente envolvida nos acidentes ofídicos, porém de acordo com os sinais clínicos, alterações laboratoriais (quadro 1) e dados epidemiológicos apresentados neste caso, os achados condizem com os acidentes ofídicos causado por serpentes do gênero Bothrops, uma vez que acidentes com serpentes do gênero Crotalus causam neurotoxicidade rápida associada a ações miotóxicas, coagulantes, nefretóxicas, ausência de necrose local, manifestações hemorrágicas discretas, paralisia motora e respiratória. Já os acidentes causados por serpentes do gênero Laquesis não apresentam alterações significativas no eritrograma e há predomínio de manifestações vagais, tais como diarréia, bradicardia, hipotensão e choque. Os sinais clínicos destes últimos dois gêneros são diferentes dos apresentados no caso relatado.

As ações hemorrágicas do veneno são decorrentes do efeito da hemorragia, que por sua vez, provoca lesões na membrana basal dos capilares, associada à trombocitopenia e a alterações da coagulação (MARQUES et al., 2003), o que justifica os sinais clínicos hemorrágicos do animal em questão. Segundo Reed e Bayly (2000), trombocitopenia e anemia são algumas das anormalidades laboratoriais que eqüinos acometidos pelo acidente ofídicopodem apresentar, tal fato corrobora com as alterações encontradas nos hemogramas realizados durante o período de internação (quadro 1), os quais demonstram valores abaixo dos de referência para a espécie, dando ênfase aos parâmetros de 2,4 milhões $/ \mathrm{mm}^{3}$ de eritrócitos; 4 g/dl de hemoglobina; $10 \%$ de hematrócrito e $98.400 \mathrm{mil} \mathrm{mm}^{3}$ de plaquetas encontrados no segundo exame realizado três dias após o acidente.

É possível que alguns animais desenvolvam anemia ocasionada pela coagulopatia e diátese hemorrágica sendo assim necessário a realização da transfusão sanguínea (CHIACCHIO et al., 2011), o que foi necessário no paciente em questão,quando foi realizada a transfusão no terceiro dia de internação pelos valores hematológicos retromencionados. A resposta ao tratamento mostrou-se satisfatória tanto na clínica, quanto nos hemogramas subsequentes. Porém, nem todos os casos transfundidos têm resultados satisfatórios, a mesma reposta e como citado por Lima et al. (2013), alguns animais podem vir a óbito mesmo após a transfusão.

Segundo Santos et al. (2003), discreta anemia decorrente de hemorragias, leucocitose com neutrofilia e desvio a esquerda, além de trombocitopenia em casos de acidente botrópico. $\mathrm{O}$ mesmo foi observado no equino em questão (quadro 1), o que levou à escolha da antibioticoterapia como tratamento à leucocitose e da transfusão sanguínea para tratar a anemia e trombocitopenia.

No perfil bioquímico é de suma importância a avaliação do comprometimento das funções renal e hepática (BOFF, 2006; PEREIRA, 2006; GOMES, 2008), pois, geralmente observa-se aumento de enzimas séricas como aspartase amino transferase (AST) (TOKARNIA ; PEIXOTO, 
2006; PUZZI et al., 2008). Tomando como guia a literatura, foram realizados exames bioquímicos periodicamente para avaliação das funções renal e hepática, através dos quais foram observados valores acima da referência para uréia, creatinina, AST e, para sua correção foram adotados uso de hepatoprotetores e fluidoterapia com solução ringer com lactato.

Conforme mencionado por Gomes (2008), apesar das alterações clínicas e hematológicas observadas nos animais acometidos, não existe testes definitivos de diagnóstico. Sendo assim, o paciente em questão foi submetido a tratamento suporte e também recebeu o soro antiofídico polivalente disponível no mercado, capaz de neutralizar venenos botrópicos, laquéticos e crotálicos ao mesmo tempo.

O edema local característico da picada por Bothrops é devido à ação direta dos componentes do veneno na microvasculatura, o que aumenta a permeabilidade de vênulas e capilares, e ao efeito dos mediadores endógenos do veneno (GUTIÉRREZ, 1998). A maioria dos sinais clínicos e laboratoriais apresentados pelo animal em questão condiz com os citados na literatura, principalmente os relacionados às reações locais como edema e hemorragias.

Segundo Chiacchioet al. (2011), o sucesso do tratamento consiste na aplicação precoce e em dose adequada de soro antiofídico por via intravenosa e na fluidoterapia, visando garantir a hidratação, melhora na perfusão renal e fornecimento de suporte cardiovascular, no entanto, tal procedimento deve ser realizado em tempo hábil para que as consequentes alterações renais e hepática não se tornem crônicas e irreversíveis.

\section{CONCLUSÃO}

Nas condições em que ocorreu este relato e, embora não se tenha determinado a espécie da serpente responsável pelo acidente, vale ressaltar que os sinais clínicos bem como os resultados hematológicos foram condizentes com a literatura pesquisada e que o tratamento foi bem sucedido, em virtude de ter sido instituído de forma rápida e por todas as complicações terem sido sanadas de forma curativa ou preventiva.

\section{REFERÊNCIAS}

ARCOLINI, T. Guias de animais brasileiros: Répteis e peixes de água doce. Editora: On-line, ano 1, n. 2, p 22-30, São Paulo, 2006.

BICUDO, P. L. In: RADOSTITS, O. M.et al. Um tratado de doença dos bovines, ovinos, suinos, caprinos e equinos. Clinica Veterinária. 9 ed. Rio de Janeiro: Ed. Guanabara Koogan. p. 15431546. 2002.

BOFF, G. J. Envenenamento por picada de serpente, gênero Micrurus (coral):revisão. Revista Veterinária em Foco, v. 6, n. 4, p. 53-62, 2006. 
CALDAS, S. A. et al. Aspectos clínico-patológicos e laboratoriais de envenenamento por Botrhops alternatus em bovinos. Pesquisa Veterinária Brasileira. v.28, n.6, p.302-312, jun 2008 .

CHIACCHIO, S. B. et al. Triple bothripic envenomation in horses caused by a single snake. The journal of Venomus Animals and Toxins. v. 17, n.1, p. 111-117, 2011.

BRASIL. Ministério da Saúde. FUNASA - Fundação Nacional de Saúde. Manual de

Diagnóstico e Tratamento de Acidentes por Animais Peçonhentos. 2 ed.Brasília. p.120, 2001.

GOMES, R. C. B. Acidente botrópico, elapídico e crotálico em cães e gatos. 2008. $23 \mathrm{f}$.

Trabalho de Conclusão de Curso (Especialização em Clínica Médica de Pequenos Animais),

Universidade Castelo Branco, Rio de Janeiro.

GRAÇA, F. A. S.et al. Aspectos clínico patológicos e laboratoriais de envenenamento crotálico experimental em bovinos. Pesq. Vet. Bras. v. 28, n.6, p. 261-70, 2008.

GRUNERT, E., GRUNERT, D. observaciones de lesiones por mordedura de serpientes

"Bothrops" enlos bovinos y caballos em Rio Grande do Sul/Brasil. Not. Med. Vet. v. 3, p. 213227. 1969.

GUTIÉRREZ, J .M., LOMONTE, B. Local tissue damaged by Bothropssnake venoms. A review. Mem. Inst. Butantan. V. 51, n. 4, p. 211-223, 1989.

LIMA, J. T. B.et al. Aidente ofidico em equino-relato de caso. In: JORNADA DE ENSINO, PESQUISA E EXTENÇÃO-JEPEX, 13. Anais... 2013. Recife. 2013.

MARQUES, M. M.; CUPO, P.; HERING, S. E. Acidente ofídico por animais peçonhentos: serpentes peçonhentas. Simpósio: Urg. eEmerg. Dermatol e Toxicológicas, cap IV, Ribeirão Preto, v.36, p. 480-489 abr./dez. 2003.

PEREIRA, M. T. Acidente botrópico em cães. 2006. 46f. Monografia (Especialização em Clínica Médica e Cirúrgica em Pequenos Animais) -Universidade Castelo Branco - Campo Grande, MS.

PUZZI, M. B.et al. Acidentes Ofídicos. Revista Científica Eletrônica de MedicinaVeterinária, v.6, n. 10, p. 1-7, 2008.

REED, S. M.; BAYLY, W. M. Medicina Interna Equina. Rio de Janeiro: Guanabara Koogan, 2000. p.877-878.

RADOSTITS, O.M., BLOOD D.C., GAY C.C. Veterinary Medicine. London, England Ballière Tindall, p. 1608-1611, 1994.

SANTOS, M. M. B.et al. Hemograma de cães envenenados experimentalmente com Bothrops alternatus após diferentes tratamentos. Revista Brasileira de Saúde e Produção Animal, v.4, n.1, p. 1-11, 2003.

TOKARNIA, C. H., PEIXOTO, P.V. A importância dos acidentes ofídicos como causa da morte em bovinos no Brasil. Pesquisa Veterinária Brasileira, p. 55-68, abr/jun. 2006. 